\title{
Early Motor Fluctuations in a Patient with Striatonigral Degeneration
}

\author{
Fumihito Yoshii Yusuke Moriya Tomohide Ohnuki Wakoh Takahashi \\ Masafuchi Ryo \\ Department of Neurology, Tokai University Oiso Hospital, Oiso, Japan
}

\section{Keywords}

Striatonigral degeneration · Motor fluctuations · Magnetic resonance imaging · Positron emission tomography

\section{Abstract}

We report a 44-year-old female with striatonigral degeneration (SND) who showed wearingoff oscillations after 4 months of levodopa treatment. The patient presented with asymmetric left-side dominant rigidity, and levodopa was effective at first. However, she began to show wearing-off oscillations of motor symptoms, which gradually worsened thereafter. Fluidattenuated inversion recovery sequence magnetic resonance imaging (MRI) showed linear lateral putamen hyperintensities, and positron emission tomography (PET) studies using ${ }^{18} \mathrm{~F}$ fluorodopa (FD) and ${ }^{11} \mathrm{C}-\mathrm{N}$-methylspiperon (NMSP) showed a marked decrease of radioactivity in the right putamen, especially in the posterior putamen. The results of MRI and 2 PET studies with FD and NMSP were well consistent with the diagnosis of SND. 


\section{Case Reports in Neurology}

Yoshii et al.: Early Motor Fluctuations in a Patient with Striatonigral Degeneration

\section{Introduction}

Motor fluctuations eventually emerge in most parkinsonian patients, and disease progression as well as early initiation and longer duration of levodopa therapy have been identified as risk factors. The incidence of motor fluctuation in patients with striatonigral degeneration (SND) is unknown. We report a SND patient who developed motor fluctuations of moderate severity during the early phase of levodopa treatment.

\section{Case Presentation}

A 44-year-old female presented with gradual onset of gait disturbance and stiffness of the left arm and leg in May 2010. The diagnosis was cervical disc herniation, and she received cervical traction and finally operation in March 2011. However, her gait disturbance and left-side limb stiffness gradually worsened after the operation. In June 2011, she was diagnosed with Parkinson disease (PD) by a neurologist at another hospital. She showed leftsided rigidity and decreased left arm swing on walking but did not show tremor. The Unified Parkinson Disease Rating Scale (UPDRS) score was 17. She was started on $100 \mathrm{mg}$ of carbidopa/levodopa per day (25/100) and had a moderate response. However, from September 2011, she began to show wearing-off oscillations of motor symptoms, and the dose of levodopa was increased to $200 \mathrm{mg}$ per day. Levodopa was effective for about $2-4 \mathrm{~h}$. The dose of levodopa was gradually increased thereafter, and other antiparkinsonian drugs such as pergolide, cabergoline, and selegiline were added to control her symptoms. However, her motor fluctuations were not improved but rather worsened, and she was referred to our hospital for further evaluation in November 2012. Her antiparkinsonian drugs at admission were as follows: levodopa $400 \mathrm{mg} /$ day, pergolide 1,500 $\mu \mathrm{g} /$ day, cabergoline $2.5 \mathrm{mg} /$ day, and selegiline $7.5 \mathrm{mg} /$ day.

Her history and family history were not contributory. Physical examinations did not show any abnormal findings. She was alert and well-oriented, and cranial nerve functions were normal. Myerson's sign was negative. Left-side limb rigidity and bilateral pyramidal signs with hyperreflexia were seen. No resting or postural tremor was observed. The fluctuation of her symptoms was definite, and drugs were effective for only around 1-2 $\mathrm{h}$. Her gait was markedly disturbed with increased left-side rigidity in "off" time.

Laboratory tests such as CBC, blood chemistry or cerebrospinal fluid were all normal. The plasma levodopa levels increased immediately after each dose of levodopa, reflecting normal absorption of levodopa from the digestive tract. The peak concentration appeared 20-30 min after drug ingestion, and the levodopa levels gradually decreased thereafter. The changes corresponded well to the fluctuation of her motor symptoms. "On" time without concomitant dyskinesia continued for 1-2 $\mathrm{h}$ when plasma levels of levodopa were high, and "off" periods occurred at times when plasma levodopa levels were low (Fig. 1).

Axial T2-weighted and fluid-attenuated inversion recovery (FLAIR) sequence magnetic resonance imaging (MRI) were performed. Linear lateral putamen hyperintensities were seen on FLAIR images but not on T2-weighted images (Fig. 2a, b).

Presynaptic and postsynaptic dopamine receptor functions in the striatum were studied with positron emission tomography (PET) using $18 \mathrm{~F}$-fluorodopa (FD) and ${ }^{11} \mathrm{C}-\mathrm{N}-$ 


\section{Case Reports in Neurology}

Case Rep Neurol 2016;8:243-250

DOI: $10.1159 / 000453254$

(C) 2016 The Author(s). Published by S. Karger AG, Basel www.karger.com/crn

Yoshii et al.: Early Motor Fluctuations in a Patient with Striatonigral Degeneration

methylspiperone (NMSP), with the written consent from the patient. In the FD study, a 30 min scan was performed $60 \mathrm{~min}$ after intravenous injection of $5 \mathrm{mCi}$ of FD to create an integrated image. It showed a marked decline of radioactivity in the right putamen (Fig. 2c), and the mean ratio of radioactivity of the right posterior putamen to that of the cerebellum was significantly decreased (Table 1). In the NMSP study, the integrated images representing radioactivity collected 45-60 min after the intravenous injection of $20 \mathrm{mCi}(740 \mathrm{MBq})$ of NMSP were analyzed. This also showed a marked decrease of uptake in the right striatum, especially in the posterior putamen (Fig. 2d), and a significant decrease in the right caudate, anterior putamen, and posterior putamen/cerebellum uptake ratios (Table 1) on the contralateral side to the predominant parkinsonian symptoms. The right/left difference was the highest in the posterior putamen among these 3 regions in the striatum.

\section{Discussion}

The differential diagnosis of patients with parkinsonism is often difficult. SND closely resembles PD, but the principal discriminating clinical features that distinguish SND from PD are early appearance of bilateral bradykinesia and rigidity, slowness of gait, postural instability and falls, absence of tremor, increased deep tendon reflexes, and dysarthria [1]. Response to adequate levodopa treatment is often poor or absent, which is attributed to a loss of striatal dopamine receptors [2]. However, Wenning et al. [3] showed that symptomatic asymmetry was seen in 74\% of the SND patients, and a good or excellent levodopa response was found at some stage in $29 \%$ of the patients. Early-onset patients (before the age of 49 years), such as our patient, often tend to have a good levodopa response [3]. So it is difficult to diagnose SND with certainty based on the clinical features only. In fact, our patient presented with asymmetric left-side dominant rigidity, and levodopa was effective at first.

An MRI pattern consisting of a hyperintense lateral rim and dorsolateral hypointense signal attenuation on the T2-weighted image is highly specific for multiple system atrophy of the SND type [4]. These signal abnormalities are not found in PD or PSP (progressive supranuclear palsy) patients and are very useful for diagnosing SND. In our patient, a linear hyperintense signal at the lateral rim of the putamen was clearly seen on FLAIR images but not on T2-weighted images. A similar observation was reported by Block and Bakshi [5] and von Lewinski et al [6] who described the better depiction of hyperintense rims in SND on FLAIR as compared with T2-weighted images. Thus, we suggest that FLAIR images should be taken into account in the differential diagnosis of patients with parkinsonism of various origins.

PET studies using FD and NMSP are useful not only for the differential diagnosis of PD and related disorders but also in understanding the pathophysiology of striatal dopamine receptor function. The decreased uptake of FD in the striatum signifies degeneration of the dopaminergic fibers from the substantia nigra. These findings are observed in both PD and SND, being based on the pathology of neuronal loss and mild-to-moderate gliosis in the substantia nigra [7]. On the other hand, in untreated PD patients, the binding potential of NMSP in the caudate, anterior putamen, and posterior putamen is normal or slightly elevated, which may reflect denervation hypersensitivity in the postsynaptic site [8]. In contrast, the binding potential is reduced in SND patients $[8,9]$. These findings correspond to the pathology of SND, which exhibits extensive nerve cell loss, gliosis, and pigmentation in the puta- 


\section{Case Reports in Neurology}

Case Rep Neurol 2016;8:243-250

DOI: $10.1159 / 000453254$

(C)

(C) 2016 The Author(s). Published by S. Karger AG, Base www.karger.com/crn

Yoshii et al.: Early Motor Fluctuations in a Patient with Striatonigral Degeneration

men and the caudate. The results of 2 PET studies with FD and NMSP in our patient were consistent with the diagnosis of SND.

Patients with idiopathic PD generally have a smooth clinical response to levodopa therapy for the first 3-5 years. However, most patients who undergo levodopa therapy eventually develop motor fluctuations following individual doses of levodopa. It is estimated that about $58 \%$ of the PD patients will develop motor fluctuations after a mean treatment period of 35 months [10]. The mechanisms responsible for motor fluctuations are not fully understood, but there are 3 major mechanisms, which may be involved [11]: (1) central pharmacokinetics or delivery of dopamine from the presynaptic to the postsynaptic receptors; (2) peripheral pharmacokinetics or delivery of levodopa from an exogenous source to the brain, and (3) pharmacodynamics or alterations in the interactions between dopamine and the striatal receptors.

Our patient's motor fluctuations developed only 4 months after the initiation of levodopa therapy, which is atypical for PD. The clinical response relies on synaptic dopamine concentration, and this becomes directly dependent on plasma levodopa levels [11]. In our patient, plasma concentration from a dose of levodopa remained within the therapeutic range only for 1-2 h. In addition, the 2 PET studies suggested that ongoing loss of presynaptic dopamine storage capacity and early alterations in postsynaptic dopamine receptor sensitivity could play an important role in the fluctuation response. Reduced striatal FD uptake indicates a reduction in the central storage capacity for dopamine in the end terminals of the presynaptic nigral cells, which impairs tonical release of dopamine. However, the patient can show a stable clinical response, if striatal receptors preserve the ability to buffer the oscillations of levodopa availability [12]. In our patient, this ability was lost at the early stage of treatment, as suggested by the decreased striatal NMSP binding. These observations are consistent with a PET study using ${ }^{11} \mathrm{C}$-raclopride, an antagonist that binds reversibly to the dopamine D2 receptor in the striatum. It was found that the mean caudate/cerebellum and putamen/cerebellum ${ }^{11} \mathrm{C}$-raclopride uptake ratios in $\mathrm{PD}$ patients with fluctuating response to levodopa were significantly reduced by 30 and $18 \%$, respectively [13].

Deep brain stimulation (DBS) is considered to be an effective surgical therapy for advanced PD with motor fluctuation [14]. Flattening of the motor fluctuations is obtained with improving general motor symptoms, especially in the "off" time. Although results following DBS can be impressive, careful patient selection is needed because SND patients may not significantly benefit from surgery. We recommend that patients who show early motor fluctuations should be studied by MRI FLAIR imaging and, if possible, PET using FD and NMSP.

\section{Statement of Ethics}

The authors have no ethical conflicts to disclose.

\section{Disclosure Statement}

The authors declare that there are no conflicts of interest to disclose. 


\section{References}

1 Gouider-Khouja N, Vidaihet M, Bonnet A-M, Pichon J, Agid Y: "Pure" striatonigral degeneration and Parkinson's disease: a comparative clinical study. Mov Disord 1995;10:288-294.

2 Fearnley JM, Lees AJ: Striatonigral degeneration. A clinicopathological study: Brain 1990;113:18231842.

-3 Wenning GK, Shlomo YB, Magalhaes M, Daniel SE, Quinn NP: Clinical features and natural history of multiple system atrophy. An analysis of 100 cases. Brain 1994;117:835-845.

$\$ 4$ Kraft E, Schwartz J, Trenkwalder C, Vogl T, Pfluger T, Oertel WH: The combination of hypointense and hyperintense signal changes on $\mathrm{T}_{2}$-weighted magnetic resonance imaging sequences. A specific marker of multiple system atrophy? Arch Neurol 1999;56:225-228.

Block SA, Bakshi R: FLAIR MRI of striatonigral degeneration. Neurology 2001;56:1200.

von Lewinski F, Werner C, Jörn T, Mohr A, Sixel-Döring F, Trenkwalder C: T2*-weighted MRI in diagnosis of multiple system atrophy. A practical approach for clinicians. J Neurol 2007;254:11841188.

7 Brooks DJ, Ibanez V, Sawle GV, Quinn N, Lees AJ, Mathias CJ, Bannister R, Marsden CD, Frackowiak RSJ: Differing patterns of striatal ${ }^{18} \mathrm{~F}$-dopa uptake in Parkinson's disease, multiple system atrophy, and progressive supranuclear palsy. Ann Neurol 1990;28:547-555.

8 Shinotoh H, Hirayama K, Tateno Y: Dopamine D1 and D2 receptors in Parkinson's disease and striatonigral degeneration determined by PET. Adv in Neurol 1993;60:488-493.

-9 Brooks DJ, Ibanez V, Sawle GV, Playford ED, Quinn N, Mathias CJ, Lees AJ, Marsden CD, Bannister R, Frackowiak RS: Striatal D2 receptor status in patients with Parkinson's disease, striatonigral degeneration, and progressive supranuclear palsy, measured with 11C-raclopride and positron emission tomography. Ann Neurol 1992;31:184-192.

McColl CD, Reardon KA, Shiff M, Kempster PA: Motor response to levodopa and the evolution of motor fluctuations in the first decade of treatment of Parkinson's disease. Mov Disord 2002;17:1227-1234. Sage JI, Mark MH: Basic mechanisms of motor fluctuations. Neurology 1994;44(suppl 6):S10-S14. Bravi D, Mouradian MM, Roberts JW, Davis TL, Sohn YH, Chase TN: Wearing-off fluctuations in Parkinson's disease: contribution of postsynaptic mechanisms. Ann Neurol 1994;36:27-31.

13 Brooks DJ, Ibanez V, Sawle GV, Playford ED, Quinn N, Mathias CJ, Lees AJ, Marsden CD, Bannister R, Frackowiak RSJ: Striatal $\mathrm{D}_{2}$ receptor status in patients with Parkinson's disease, striatonigral degeneration, and progressive supranuclear palsy, measured with ${ }^{11} \mathrm{C}$-raclopride and positron emission tomography. Ann Neurol 1992;31:184-192.

14 Fox SH, Katzenschlager R, Lim SY, Ravina B, Seppi K, Coelho M, Poewe W, Rascol O, Goetz CG, Sampaio C: The movement disorder society evidence-based medicine review update: Treatments for the motor symptoms of Parkinson's disease. Mov Disord 2011;Suppl 3:S2-S41. 


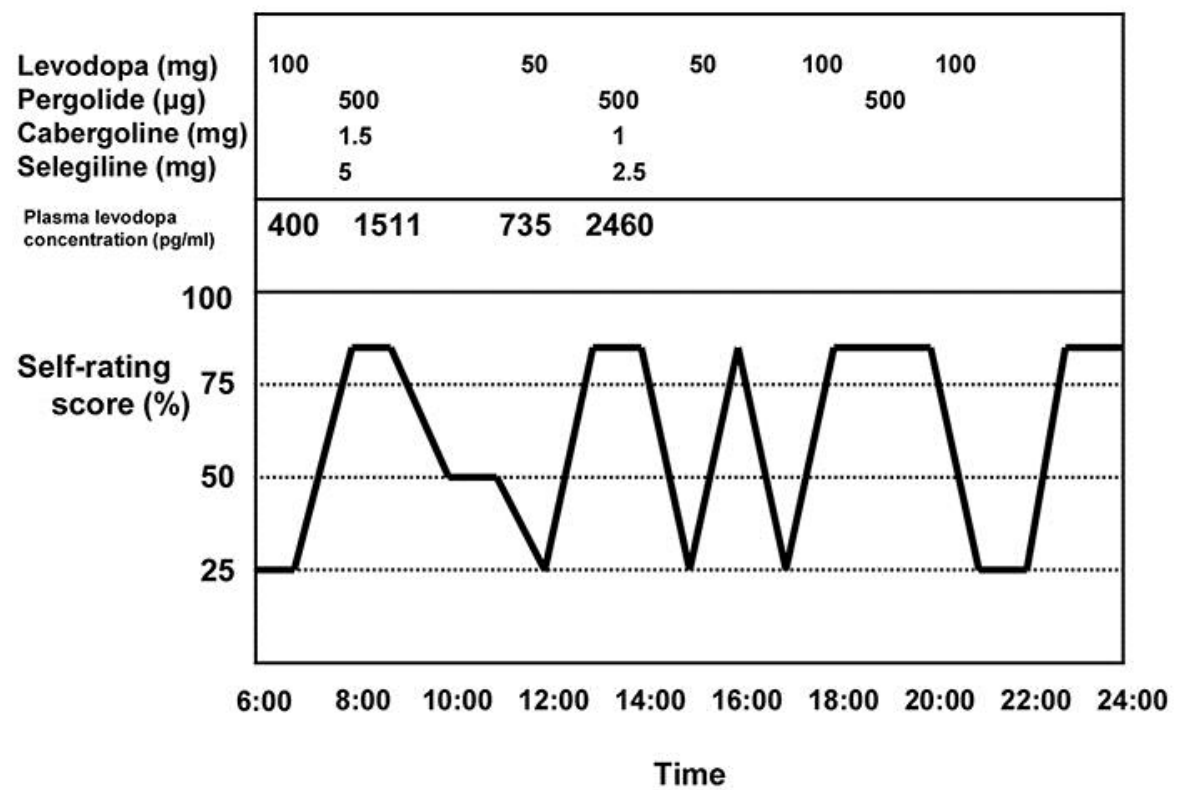

Fig. 1. Diurnal changes of motor symptoms in relation to the ingestion of antiparkinsonian drugs. Plasma dopamine concentrations are also shown. 


\section{Case Reports in Neurology}
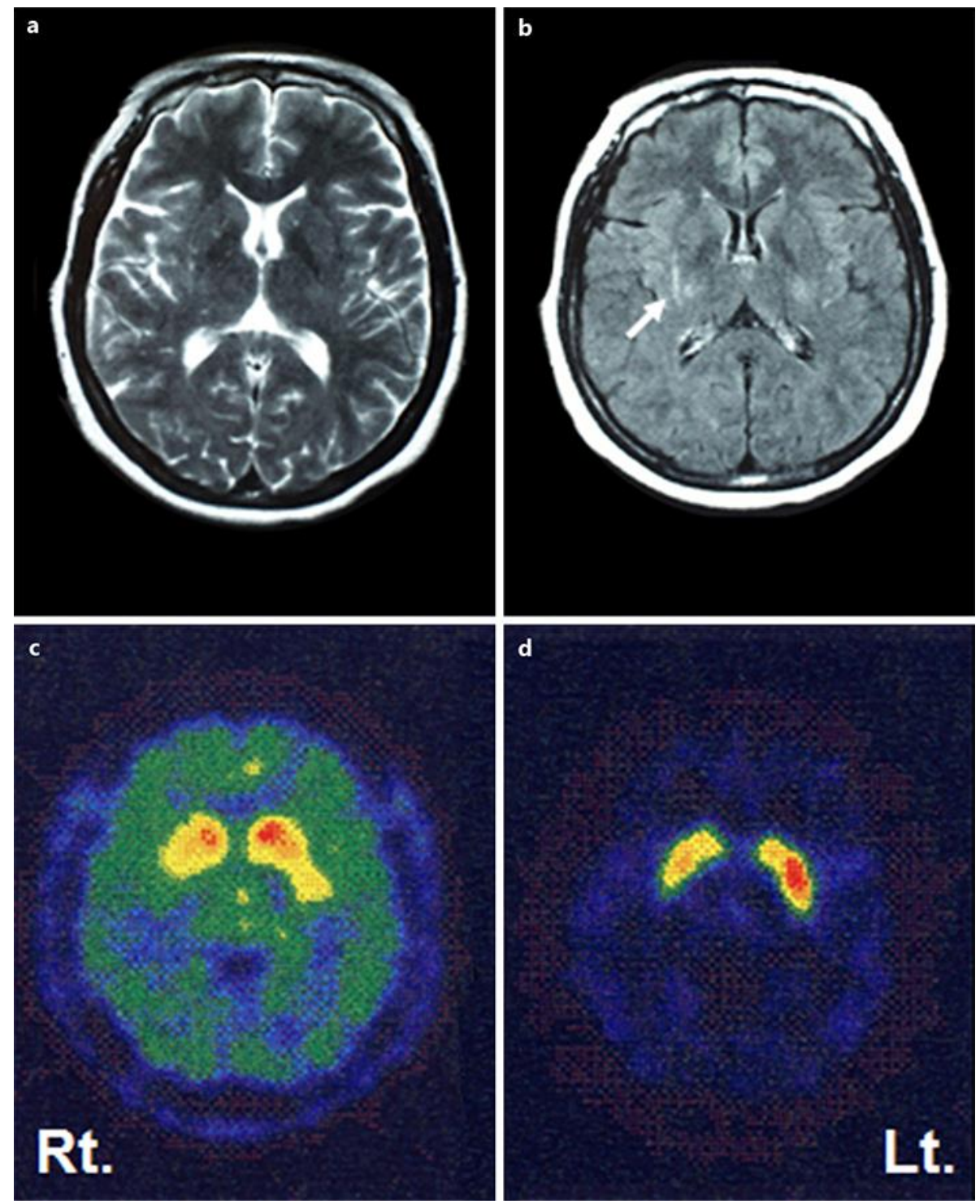

Fig. 2. MRI and PET. a T2-weighted image (repetition time [Rt]: 3,758 $\mathrm{ms}$, echo time [Et]: $120 \mathrm{~ms}$ ) at the striatal level does not clearly show signal changes at the lateral rim at the dorsolateral border of the putamen. b FLAIR image (Rt: 6,000 ms, Et: $150 \mathrm{~ms}$ ) shows a pathological hyperintense signal at the lateral rim of the right putamen. $\mathbf{c}$ PET with FD shows a decrease of radioactivity in the right putamen. $\mathbf{d}$ PET with NMSP shows a marked decrease of uptake in the right striatum, especially in the posterior putamen. MRI, magnetic resonance imaging; PET, positron emission tomography; FLAIR, fluid-attenuated inversion recovery; FD, ${ }^{18} \mathrm{~F}$-fluorodopa; NMSP, ${ }^{11} \mathrm{C}$-N-methylspiperon. 
Table 1 . Uptake ratios of the striatum/cerebellum by 2 positron emission tomography studies

\begin{tabular}{lcc}
\hline & Right & Left \\
\hline FD uptake ratios & & \\
$\quad$ Caudate/cerebellum & 1.71 & 1.79 \\
$\quad$ Anterior putamen/cerebellum & 1.51 & 1.47 \\
$\quad$ Posterior putamen/cerebellum & 1.19 & 1.39 \\
NMSP uptake ratios & & \\
$\quad$ Caudate/cerebellum & 3.86 & 4.40 \\
$\quad$ Anterior putamen/cerebellum & 4.46 & 5.04 \\
$\quad$ Posterior putamen/cerebellum & 3.65 & 4.57 \\
\hline
\end{tabular}

FD, ${ }^{18}$ F-fluorodopa; NMSP, ${ }^{11} \mathrm{C}$-N-methylspiperone. 